\title{
Quality Assessment of Oil Used for Frying of Potato Chips: In the Case of Wolkite University Community
}

\author{
Solomon Duguma, Gashaw Abebaw \\ Department of Food Process Engineering, College of Engineering and Technology, Wolkite University, Wolkite, Ethiopia \\ Email address: \\ solex.duguma@gmail.com (S. Duguma),gashaw11abebaw@gmail.com (G. Abebaw)

\section{To cite this article:} \\ Solomon Duguma, Gashaw Abebaw. Quality Assessment of Oil Used for Frying of Potato Chips: In the Case of Wolkite University \\ Community. American Journal of Bioscience and Bioengineering. Vol. 8, No. 5, 2020, pp. 92-98. doi: 10.11648/j.bio.20200805.12
}

Received: October 12, 2020; Accepted: October 22, 2020; Published: November 23, 2020

\begin{abstract}
Frying is an old and widely used method of cooking and processing food. Typically, a food is immersed in heated oil for a short duration in a process known as immersion-oil frying. Consumers tend to associate color with flavor, safety, storage time, nutrition, and level of satisfaction, due to the fact that color correlates well with physical, chemical, and sensorial evaluations of food quality. Indicators of poor oil quality include elevated FFA, low smoke point, change of color, low iodine value, peroxide value, total polar material, high foaming properties and increased viscosity. Deep frying and the use of recycled oil for many times is a commonly practiced in commercial and sometimes in domestic cooking processes. The way of this cooking method may create a lipid peroxidation product which brings harm to human health. Quality assessment of oil used for frying of potato chips in the case of Wolkite university community studied. The result of physicochemical properties of oil were investigated from sample selected randomly around Wolkite town and these are free fatty acid, peroxide value, smoking point and iodine value of recycled oils was higher than the recommended values. The strength of current evidence makes it reasonable to recommend complete avoidance of fried foods or at most infrequent to moderate fried food consumption within the context of an overall healthy dietary pattern around Wolkite town. Generally, the present study shows the recycled oil used were not as standards of FAO and also the people of fried food makers were not having awareness about the impacts of recycled oils.
\end{abstract}

Keywords: Fat, Oil, Recycled and Frying

\section{Introduction}

Frying is an old and widely used method of cooking and processing food. Typically, a food is immersed in heated oil for a short duration in a process known as immersion-oil frying. Numerous type of edible oils of plant and animal origin are used in frying. During the last five decades, the Western food industry has become increasingly dependent on the frying process to manufacture a variety of snack foods. Fried foods such as potato chips, French fries, and fried fish and chicken have gained worldwide popularity. A wide variety of products are fried on an industrial scale. Among the most popular are potato chips (also called potato crisps), expanded snacks, roasted nuts, French fries (also called potato chips), extruded noodles, doughnuts, and frozen foods covered with batter, such as fish \& chicken. In the potato chip industry, the quality of each batch of potato tubers must be tested before processing, and of the various quality criteria the visual aspect, especially the color, is of great importance [1]. Color of potato chips is the first quality parameter evaluated by consumers, and is critical in the acceptance of the product. Consumers tend to associate color with flavor, safety, storage time, nutrition, and level of satisfaction, due to the fact that color correlates well with physical, chemical, and sensorial evaluations of food quality. Indicators of poor oil quality include elevated FFA, low smoke point, change of color, low iodine value, peroxide value, total polar material, high foaming properties and increased viscosity [2]. Restaurants and other food services had monitored the changes in physical properties of frying oils which used as an indicator of oil quality. For example, sample of frying oil could be discarded if the oil presented in dark, too much smoke, strong odor, greased texture, or when a persistent foam layer of specified thickness is observed. Nevertheless, before an operator found the physical effects, the oil has typically undergone considerable decomposition [3]. 
Oxidation is a major deteriorating process that gives huge implication in the conditions of the quality and assessment such as developing the rancidity and off-flavor of fats and oils [4]. Basically, frying oils undergo common degradation and complex chemical alteration when heated. Acceleration of the deterioration in frying oil and also producing a number of polar molecules as resulted by viscosity and density data of oils can be caused by the presence of air and water. Hydroperoxide is from the formation of primary oxidation products that develop from triacylglycerol, which may later decompose in order to become lower molecular weight compounds like free fatty acids, alcohols, aldehydes, and ketones which ultimately leading to a rancid product[5]. In addition, the oxidation process that occurs in oils, whether in storage or heating, condition may contribute in low nutritional quality, alter the flavor and may generate toxic compound [6]. Indeed, [7] claimed that, higher temperature use during frying can make the oil form a radical compound that give bad impact to health. Therefore, the peroxide compound in deep-frying cooking oil has been measured. Acrylamide, which is formed in potatoes during frying and is highly related to the color of potato chips, is suspected to have critical implications for human health, since it has recently been found to be a carcinogen in rats [8]. Potato chip color is affected by the Maillard reaction, which depends on the content of reducing sugars, amino acids, or proteins at the surface. Generally, potato tubers that contain more than 2 percent of reducing sugars are discarded for frying, since they generate too dark a coloration. In general, foods rich in carbohydrate and prepared at temperature above $160^{\circ} \mathrm{C}$ exhibit acrylamide formation and this may be related to the degree of browning. Browning is a result of a series of reactions known as Maillard reaction. Maillard reaction, apart from providing desirable color, contributes to the flavor and aroma of the final product. Studies conducted so far indicated that foods with high carbohydrate content such as potatoes, develop high levels of acrylamide when heated at high temperature. It has been suggested that the amino acid asparagine and reducing sugars in Maillard reaction accounted for the majority of acrylamide in potato products.

\subsection{Statement of the Problem}

Deep frying and the use of recycled oil for many times is a commonly practiced in commercial and sometimes in domestic cooking processes. The way of this cooking method may create a lipid per oxidation product which brings harm to human health. Most of the products are non-volatile, so they will be remained in the food or oils and give effect to the physical properties and form other radicals. This is due to the high temperatures in the existence of air and moisture, which make the occurrence of oxidative degradation of amino acids and the partial conversion of these lipids to volatile chain-scission products, non-volatile oxidized derivatives and polymeric or cyclic substances leading to the formation of toxic or carcinogenic compounds [9]. Therefore, this action research gives an overview of some commonly consumed fried products (potato chips) in Wolkite University, the effects of thermal oxidation on quality of oil used and possible health implications.

\subsection{General Objective}

To assess the quality of recycled oil used for frying of potato chips in the case of Wolkite University community.

\subsubsection{Specific Objectives}

1. To study chemical quality of recycled oil used of frying

2. To asses awareness of Wolkite university community in relation to the quality of oils used for frying

\subsubsection{Significance of the Study}

This particular action research had a great role on alleviating health problems related to fried food consumption specially potato chips by creating awareness to Wolkite town. As a result, the society consuming potato chip will be changed and take consideration of the status of the oil used for frying purpose. Since the oil quality has a considerable effect on the human health, acceptability and nutritional value of potato chips. In addition, the findings of this action research will give direction for further researches.

\section{Literature Review}

\subsection{Application of Oils for Frying}

The use of oil or fat for frying of food around the world, as confirmed by the increasing number of fast food restaurants and at home. Also, edible oil is a source of energy and essential fatty acids (FAs) and serves as a carrier of fatsoluble vitamins [10]. Fried foods are popular because of their rapid and easy production. Furthermore, fried foods are highly appreciated by consumers because owing to their appealing sensory properties such as color, flavor, texture, and palatability [11]. Regular consumption of deep-fried foods such as french-fries, fried chicken, and doughnuts has recently increased with economic development and a change in eating habits. Deep frying involves simultaneous heat and mass transfers in the food processing operation by immersing the food as a whole into the hot oil at temperatures of $180^{\circ} \mathrm{C}$ or higher [12]. However, during the frying process, oil or fat is often recycled for several batches, allowing moisture and air to be mixed into the hot oil. As a result, these fats and oils undergo thermal and oxidative decomposition, and polymers formed under these conditions are harmful to health [13]. The associated reactions increase the viscosity of the oils, darken their color, increase the foaming, and decrease the smoke point. Overall, deep-frying deteriorates the quality of the oil. The choice of frying oil or fat depends on many factors such as availability, price, frying performance, flavor, and stability of the product during storage. The most popular oil used for frying products is palm oil (PA) or its fraction, followed by soybean oil (SB), canola oil (CA), and lard (LA). Hydrogenated vegetable oils such as sunflower and rapeseed oil are also [14]. Abused frying oils may contain harmful concentrations of degradation products, and so, frying oil quality is also a very important issue concerning food safety and consumers' health [15]. 


\subsection{Quality of Cooking Oil}

Edible oil is one of the chosen ingredients of the diet that used for cooking purposes. Researchers had studied the effect of temperature on the stability, viscosity, peroxide value, and iodine value to assess the quality and functionality of the oil [16]. It is necessary to observe the quality of oil in order to avoid the use of abused oil, bad health consequences due to high consuming foods fried in degraded oil, to keep the quality of fried foods and to minimize the production costs associated with early disposal of the frying medium. Oil that rich with unsaturated fatty acids may allowed in rapid degradation because of the oxidation activity [17], Atmospheric oxygen responds instantly with lipid and other organic compounds of the oil to cause structural degradation in the oil, which leads to loss of quality of food and is harmful to human health (Bhattacharya et al., 2008). Besides, the occurrence of hydrolysis is generally caused by the present of water that came from the fried food [18]. Then, increasing of free fatty acid value is mainly from the degradation of secondary oxidation products formed during heating and the presence of oxygen. The existence of moisture that may be provided by air could have an influence on increasing acidity. However, the drop off in the acidity level after $24 \mathrm{~h}$ and $30 \mathrm{~h}$ may be caused by the evaporation of the volatile free fatty acids under the heating effect. The polymerization of fatty acids during the heating process may also block the acid functions that are no longer assayed [19]. A various type of physical and chemical parameters of edible oil was used to examine the compositional quality of oils [20]. These physicochemical parameters include iodine value (IV), saponification value (SV), viscosity, density and peroxide value (PV) [21] clarified about hydrolytic rancidity that happen due to hydrolysis of fats and oils and it has potential in yielding free fatty acid (FFA). The level of acidity in $1 \mathrm{~g}$ of sample can be determined by neutralize the FFA using milligrams of potassium hydroxide. A part from that, Europe is the only state in the world that has guidelines on frying oil safety [22]. Furthermore, the color change in oils is mainly caused by an accumulation of highly conjugated oxidation products. Color was closely correlated with all the assessed parameters. However, it needs to be considered with color measurement because they could be influenced by pigments extracted from the food [23].

\subsection{Parameter in Measuring the Oil Quality}

\subsubsection{Viscosity and Density Measurement}

A quality of fried food is also corresponding with the using oil because as the oil degrades, it will be changing the quality of the food products. Now a day, there are many physical test and chemical test found in the food industry. One of the methods and instrument that available to check on the oil quality is by measuring the viscosity. The designed instrument was to measure the formation of polymerized and oxidized matter (POM) contained in used cooking oil [23]. The viscosity of oils refers to the present of complex triglyceride (TGs) that is naturally present in oils. The alteration of fatty acids arrangement on the glycerol backbone of the triglyceride molecule can change the viscosity of the oils. Consequently, the chain length with the chemical properties of saturated and unsaturated chain give affects to the viscosity of oils [24]. Moreover, the viscosity and density decrease with an increase of unsaturation chain [25]. Sheer stress and temperature are also related to viscosity. However, sheer stress does not give much effect toward storage of oils which are used for edible purposes compared to the effect of temperature. When the temperature goes high the kinetic energy will be also increase to enhance the movement of the molecules and lowered the intermolecular forces. The layers of the liquid easily pass over one another and thus contribute to the reduction of viscosity. This nature is also revealed by another study that discussed the viscosity is depends on the molecular structure and decreases with the unsaturation of fatty acids [26]. The density of oils will be decreased when the temperature is arisen as well as when using the same oil for frying three times. The densities of oils were related to the standard range of $0.898-0.907 \mathrm{~g} / \mathrm{ml}$ approved by the Standard Organization of Nigeria (SON, 2000). Frying process could undergo thermo-oxidative or lipid oxidation and hydrolytic reactions which results in deterioration in quality of the oil [27].

\subsubsection{Saponification Value Measurement}

Saponification value (SV) is an index of an average molecular mass of fatty acid in the oil sample. The lower value of saponification represent that the mean molecular weight of fatty acids is lower or that the number of ester bonds is less. This might imply that the fat molecules did not interact with each other.

\subsubsection{Iodine Value Measurement}

Iodine value (IV) is a measure the degree of unsaturation in a fat or vegetable oil. It verifying the oxidative stability of oils and can qualitatively determine the whole unsaturation of fats [29]. The result of low iodine values can contribute to its greater oxidative storage stability [28].

\subsubsection{Free Fatty Acid Measurement}

There are several methods to investigate the quality of oil is such as by measuring the free fatty acid (FFA) and total polar compound level [29]. FFA levels represent the mechanism of triacylglycerol elements had undergone hydrolytic degradation. Generally during the refining process, high level of FFAs compounds could be removed from the crude oils. Stated that, the refined oil has to be $0.1 \%$ less of FFA content. When the content of FFAs in frying oil is more than $1 \%$, it is suggested to be discarded. Furthermore, the oils could be discarded if the FFA content had reached to $2 \%$ as claimed by the United States Department of Agriculture. Other than that, the limit of FFA in frying oil that have been proposed by some of the European countries as their regulatory rule ranging from 1.0 to $2.5 \%$.

\subsubsection{Peroxide Value Measurement}

Peroxide value $(\mathrm{PV})$ is related in measuring rancidity 
reactions and can be used as an indication of the quality and stability of fats and oils. The peroxide value could increase corresponds with the storage time, contact with air of the oil samples and temperature [30]

\section{Materials and Methods}

The experiment of oil quality determination was conducted at Wolkite University in Food Process Engineering laboratory. And survey assessment was conducted at Wolkite University community.

\subsection{Experimental Materials and SAMPLING}

Oil samples were acquired from Wolkite town fried products makers. The acquired samples were selected based on random sampling techniques.

\subsection{Methods}

Percentage of free fatty acids, peroxide value, smoking point and iodine value were determined using the [31] in triplicate sample.

\section{Results and Discussions}

\subsection{Dietary Quality Survey on Oil Fried Food Product Consumption}

This Summary Report describes the methods used and the main findings with regard to fried food consumption, types of oil used, and health impacts of the oil recycled for frying. The survey was carried out by the Wolkite University community.

Table 1. Dietary quality survey on oil fried Food product consumption.

\begin{tabular}{|c|c|c|c|}
\hline No. & Question Type & Frequency & Percentage \\
\hline \multirow{3}{*}{1} & Do you know saturated and unsaturated oils? & 42 & 100 \\
\hline & Yes & 28 & 66.67 \\
\hline & No & 14 & 33.33 \\
\hline \multirow{3}{*}{2} & Do you know how they can be prepared/processed? & 42 & 10 \\
\hline & Yes & 42 & 100 \\
\hline & No & 0 & 0 \\
\hline \multirow{3}{*}{3} & Do you agree all fried products are produce under a sanitary condition in Wolkite town? & 42 & 100 \\
\hline & Yes & 12 & 28.57 \\
\hline & No & 30 & 71.43 \\
\hline \multirow{3}{*}{4} & Do you ever asked the type and quality of oil used for frying? & & \\
\hline & Yes & 10 & 23.81 \\
\hline & No & 32 & 76.19 \\
\hline \multirow{3}{*}{5} & All fats and oils are used for frying purpose & 42 & 100 \\
\hline & Yes & 36 & 85.71 \\
\hline & No & 6 & 14.29 \\
\hline \multirow{3}{*}{6} & Do you know any health problems with the consumption of fried products & 42 & 100 \\
\hline & Yes & 31 & 73.81 \\
\hline & No & 11 & 26.19 \\
\hline \multirow{4}{*}{7} & Which of the product are you know from fried products & & \\
\hline & Potato chips & 42 & 100 \\
\hline & Bonbolino & 42 & 100 \\
\hline & Sanbusa & 42 & 100 \\
\hline \multirow{4}{*}{8} & How long do you have an experience on consumption of oil fried products? & 42 & 100 \\
\hline & $1-5$ year & 4 & 9.52 \\
\hline & 6-10 Year & 27 & 64.29 \\
\hline & More than 10 year & 15 & 35.71 \\
\hline \multirow{5}{*}{9} & How many meals fried products do you usually serve each day? & 42 & 100 \\
\hline & One & 6 & 14.29 \\
\hline & Two & 15 & 35.71 \\
\hline & Three & 9 & 21.43 \\
\hline & Four & 10 & 23.81 \\
\hline \multirow{5}{*}{10} & On what basis do you prefer best quality of fried products? & 42 & 100 \\
\hline & Flavor & 3 & 7.14 \\
\hline & Color & 12 & 28.57 \\
\hline & Crispiness & 12 & 28.57 \\
\hline & Oily & 0 & 0 \\
\hline \multirow{3}{*}{11} & Do you observe some black/charred materials on fried products? & 42 & 100 \\
\hline & Yes & 38 & 90.48 \\
\hline & No & 4 & 9.52 \\
\hline
\end{tabular}

The study population consisted of 42 respondents of which $66.67 \%$ (28) knows saturated and unsaturated oils and $33.33 \%$ (14) haven't know how about saturated and unsaturated oils. So, the type of oil has its own health impact and WHO recommends limiting the consumption of saturated and transfats (hydrogenated fats), sugars and salt in the diet, which are often found in snacks, processed foods and drinks [35]. Healthy diets should provide very low intake of TFAs (i.e., 
$<1 \%$ ), adequate intake of polyunsaturated fatty acids (PUFAs) (i.e., $6 \%-10 \%$ of daily energy intake), with an optimal balance between intake of n-6 PUFAs (5\%-8\% of daily energy intake) and n-3 PUFAs (1\%-2\% of daily energy intake) [36]. Our study includes type and quality of oils used for frying and health problems of fried products like potato chips, bonbolino and sanbusa. From the survey result the quality of oil used for frying $76.18 \%$ (32) respondents were not ask the quality of the oil used even if they didn't ask the quality of the oil during purchase they knows health impacts almost all respondents. So, the survey result shows the effects of fried foods include a lack of detailed information on the type of oils used for frying foods, differentiation between the different types of fried foods, frying procedure (deep and pan frying), temperature and duration of frying, how often oils were reused and a lack of consideration of overall dietary patterns. frying is generally considered an unhealthy way of preparing food leads to changes in quality attributes in fried food products and needs sanitary conditions because fat are exposed to chemical reactions (rancidity). The currents study shows $71.43 \%$ (30) of respondents agreed fried food production were not be processed under sanitary conditions. Changes in lifestyle and changes in unhealthy cooking habits from frying to boiling have been found to be beneficial for controlling blood pressure and obesity in the general population [32]. So, unhealthy fried food production causes health impact like coronary heat disease, hypertension and obesity.

The quality of oil used for frying have an impact on the quality of finished products (color) but the current study shows $90.48 \%$ (38) respondents were observed charred/black material on the finished products. When the fried products have black or charred color this shows reactions can takes place (Millard reaction). So, this is may be due to the type of oil, frying temperature, type of fried product and the environments [33].

\subsection{Quality Indicators of Fried Oils}

\subsubsection{Peroxide Value}

All samples that collected before frying showed a high value of peroxide which is started from 2.976, 2.997, 2.993, $2.268,3.319$ and 2.329, for sample 1 to 6 respectively. The peroxide value of oil was kept increasing after it's used in frying until the value were reached from 11.982, 14.662, $17.321,19.975,22.581$ and 22.639 in sample 1 to 6 respectively. The maximum level suggested by FAO of United Nation (2013) is up to 10 milliequivalents of active oxygen $/ \mathrm{kg}$ oil in refined oil. The increase in peroxide value was also suggested that the peroxide form during the storage condition. Furthermore, the lipid hydroperoxide radical is formed when the heated oil is kept at room temperature and reused again in frying [34]. Freshly refined oils regularly have a PV, lower than $1 \mathrm{meq} / \mathrm{kg}$ oil and oil is considered to be rancid at a peroxide value above $10 \mathrm{meq} / \mathrm{kg}$ oil. [37] reported that a good quality frying vegetable oil should have a PV of less than $2 \mathrm{meq} / \mathrm{kg}$. Studied done in-use frying oils collected during frying operations showed that PV ranges from 3.3 to $48.1 \mathrm{meq} / \mathrm{kg}$. Then, in discarded samples the PV ranged from 4.7 to $247.5 \mathrm{meq} / \mathrm{kg}$ [38]. This can prove that a large proportion of the frying oils used in these commercial establishments were highly oxidized [35].

\subsubsection{Free Fatty Acid (FFA)}

Free fatty acid (FFA) is widely used by many food processors as an indicator of oil deterioration. This is because the method is relatively fast and reliable for monitoring the acidity of oil during frying [39]. FFA represents the percentage of fatty acids liberated from the triglyceride chain during heating due to hydrolysis and oxidation [40]. The formation of FFA is highly associated with the smoke point, with an increase in FFA content lowering the smoke point [36].

According to the result finding for FFA sample 1 to 6 before the oil used for frying the value were ranged from 0.9 , $0.86,0.64,0.68,0.47$ and $0.77 \%$ respectively. The value of FFA in oil was kept increasing after it's used in frying until the value were reached from $2.182,1.662,1.961,1.842$, 2.281 and $2.132 \%$ in sample 1 to sample 6 respectively. Many researchers have reported an increase in FFA levels during frying which was due to the cleavage and oxidation of double bonds to form carbonyl compounds with the latter oxidizing to form low molecular fatty acids during frying experiments. The maximum allowed value of FFA varies depending on the type of food being fried. For the industrial production of potato chips, an FFA of $0.3 \%$ has been reported as the threshold for discarding used frying oil, whereas a maximum value of $1 \%$ FFA is usually allowed by the processors of pre-fried French fries (Ismail, 2005). Some countries even have regulation on the FFA threshold to discard frying oil: for example, Austria (1.25\%), Belgium $(2.5 \%)$, Germany (1\%), Japan (1.25\%) and the Netherlands $(2.25 \%)$.

\subsubsection{Iodine Value}

The iodine value is a measure of unsaturation. A decrease in the iodine value is consistent with a decrease in the number of double bonds in heated oil as it becomes oxidized. The IV of oil sample from 1 to 6 used for frying purpose were ranged from 103, 94.6, 78.2, 62.91, 84.64 and 79.48 IN before frying. A change in IV were observed after a few days of frying in all oil's samples (1 to 6) 92.3, 89.95, 71.48, 56.8, 73.67 and $69.99 \mathrm{IN}$ respectively. The differences in iodine values of the oil during frying are also indicative of the increased rate of oxidation during frying. According to [37], a significant change in the iodine values can be observed when there is excessive deterioration of the oil.

\subsubsection{Smoke Point}

The smoke point of fat/oils are indicator of temperature at which a fat first starts to smoke. For most fats/oils, it is 216$232^{\circ} \mathrm{C}$ but it is lower for high lauric fat, emulsified fat and emulsifies. According to the finding the smoke point of repeated use of oils for frying purpose were decreased from $205,221,198,177,215$ and $200^{\circ} \mathrm{C}$ for sample 1 to 6 respectively. These results agreed with Termizi and Siew, 2008 lowering the smoke point were observe during repeated use of oils and an increase of FFA. 


\section{Conclusions}

The physicochemical properties of oil were investigated from sample selected randomly around wolkite town and these are free fatty acid, peroxide value, smoking point and iodine value of recycled oils. So, the present study shows that the oils used are not recommended as standards. The strong evidence suggestion and association of fried food consumption with a higher risk of developing chronic disease in adults. The strength of current evidence makes it reasonable to recommend complete avoidance of fried foods or at most infrequent to moderate fried food consumption within the context of an overall healthy dietary pattern. Generally the present study shows the recycled oil used were not as standards of FAO and also the people of fried food makers were not have awareness about the impacts of recycled oils.

\section{References}

[1] Andrikopoulos N. K., Boskou G., Dedoussis G. V. Z., Chiou A., Tzamtzis V. A., Papathanasiou A. Quality assessment of frying oils and fats from 63 restaurant in Athens, Greece. Food Serv. Tech. 2003; 3:49-59.

[2] Belitz, H.-D., Grosch, W. and Schieberle, P., 2004. Food Chemistry, 3rd ed. Springer-Verlag, Berlin. pp. 218-219.

[3] Choe, E. and Min, D. B., 2007, Chemistry of Deep-Fat Frying Oils. Journal of Food Science, 72: 77-86.

[4] Choudhary M., Grover K. Effect of deep-fat frying on physicochemical properties of rice bran oil blends. IOSR J. Nuts. Health Sci. 2013;1:1-10.

[5] Debnath S., Rastogi N. K., Gopal Krishna A. G., Lokesh B. R. Oil partitioning between surface and structure of potato slicesa kinetic study. Food Sci. Technol. 2009;42:1054-1058.

[6] Debnath S., Rastogi N. K., Gopala Krishna A. G., Lokesh B. R. Effect of frying cycles on physical, chemical and heat transfer quality of rice bran oil during deep-fat frying of poori: An Indian traditional fried food. Food Bioprod. Process. 2012;90:249-256.

[7] Dobarganes M. C., Perez-Camini M. C., Marquez-Ruiz G., Velasco J. Interactions between fat and food during deepfrying. Eur. J. Lipid Sci. Technol. 2000;102:521-528.

[8] Farid M. M. A unified approach to the heat and mass transfer in melting, solidification, frying and different drying processes Chem. Eng. Sci. 2001;56:5419-5427.

[9] Fullana, H. R., A., Sidhu, S. and Carbonell-Barrachina, A. A. 2009. Emissions of volatile aldehydes from heated cooking oils; Food Chemistry 120: 59-65.

[10] Garrido-Polonio C, Garcia-Linares MC, Garcia-Arias MT, Lopez-Varela S, Garcia-Katragadda, Yang CM, Grey AA, Archer MC, Bruce WR. 1998. Rapid quantitation of thermal oxidation products in fats and oils by $1 \mathrm{H}-\mathrm{NMR}$ spectroscopy. Nutr Cancer, 30(1): 64-68.

[11] Ghidurus M., Turtoi M., Boskou G., Niculita P., Stan S. Nutritional and health aspects related to frying (I) Rom. Biotech. Lett. 2010;15:5675-5682.
[12] Good, J. 2012. "Healthiest Cooking Oil Chart With Smoke Points, Baseline of Health Foundation" https://www.jonbarron.org/article/healthiest-cooking-oil-chartsmokepoints.

[13] Gotoh, N., Ai-Iwasawa, H. Watanabe, R. Osato and S. Wada, 2007. Oxidation of fats and oils in instant noodles stored under various conditions. Journal of Food Lipids, 14: 350-365.

[14] Gupta, M. K. (2005). Frying oils. In F. Shahidi (Ed.). Bailey's industrial oil and fat products, A John Wiley and Sons Inc. Publication. New Jersey, pp. 1-32.

[15] IARC, (1994). Acrylamide. Monographs on the evaluation of carcinogenic risks to humans: Some industrial chemicals, Lyon, France. 60, pp. 389-433.

[16] Kristott J. High-oleic oils how good are they for frying. Lipid Tech. 2003; 3:29-32.

[17] Kisioglu, A. N.; Aslan, B.; Ozturk, M.; Aykut, M.; Ilhan, I. Improving control of high blood pressure among middle-aged Turkish women of low socio-economic status through public health training. Croat Med. J. 2004, 45, 477-482.

[18] Lapointe A, Couillard C, Lemieux S. Effects of dietary factors on oxidation of low-density lipoprotein particles. Journal of Nutritional Biochemistry 2006; 17(10): 645-658.

[19] Lin, S., Akoh, C. C. and Reynolds, A. E. (1998). The recovery of used frying oils with various adsorbents. Journal of Food Lipids, 5, 1-16.

[20] Marique T, Pennincx S, Kharoubi A (2005) Image segmentation and bruise identification on potatoes using a Kohonen's self-organizing map. Journal of Food Science, 70, 415-417.

[21] Mensah, E. and Obeng, G. Y., 2013. Assessment and Projection of Waste Vegetable oils from Hotels for Biodiesel Feedstock and $\mathrm{CO} 2$ Savings in Ghana. International Journal of Engineering Research and Science \& Technology, Vol. 2, No. 4 (1-12), ISSN 2319-5991.

[22] Moreira, R. G., Castell-Perez, M. E. and Barrufet, M. A. 1999. Deep-Fat Frying: Fundamentals and Applications. Aspen Publishers, Gaithersburg, MD.

[23] Nishida, C.; Uauy, R.; Kumanyika, S.; Shetty, P. The joint who/fao expert consultation on diet, nutrition and the prevention of chronic diseases: Process, product and policy implications. Public Health Nutr. 2004, 7, 245-250.

[24] Pedreschi F, Moyano PC, Kaack K, Granby K (2005) Color changes and acrylamide formation in fried potato slices. Food Research International, 38, 1-9.

[25] Pedreschi F, León J, MeryD, Moyano P (2006) Implementation of a computer vision system to measure the color of potato chips. Food Research International, in press.

[26] Prakash K. N., Uma D., Kalpana R., Keasvan R. K. Physiochemical change during repeated frying of cooked oil: A Review. J. Food Biochem. 2016; 3:371-390.

[27] Romero, A., Bastida, S., and Sanchez-Muniz, F. J., 2006. Cyclic fatty acid monomer formation in domestic frying of frozen foods in sunflower oil and high oleic acid sunflower oil without oil replenishment. Food and Chemical Toxicology44: 1674-1681. 
[28] Rosen, J. and Hellenas, K. E. (2002). Analysis of acrylamide in cooked foods by liquid chromatography tandem mass spectrometry. Analyst, 127, 880-882.

[29] Rossell J B., 1998. "Industrial Frying Process. Grasas y Aceites, Vol. 49 Fasc. 3-4, pp. 282-295.

[30] Rossi M., Alamprese C., Ratti S. Tocopherols and tocotrienols as free radical-scavengers in refined vegetable oils and their stability during deep-fat frying. Food Chem. 2007; 102:812817.

[31] Seo H. W., Kim G. D., Jung E. Y., Yang H. S. Quality properties of beef patties replaced tallow with rice bran oil and olive oil during cold storage. Korean J. Food Sci. An. 2011; 31:763-771.

[32] Soriguer F, Rojo-Martinez G, Dobarganes MC et al. 2003. Hypertension is related to the degradation of dietary frying oils. The American Journal of Clinical Nutrition, 78: 1092-7.
[33] Stadler RH, Blank I, Varga N, Robert F, Hau J, Guy PA, et al. Food Chemistry: Acrylamide from Maillard reaction products. Nature 2002; 419:449 - 50.

[34] The Joint Institute for Food Safety and Applied Nutrition (JIFSAN). Acrylamide in Food Workshop: Scientific Issues, Uncertainties and Research Strategies. Maryland: JIFSAN; 2002.

[35] Weisshaar R. Quality control of used deep-frying oils. Eur. J. Lipid Sci. Technol. 2014; 116:716-722.

[36] Wedzicha DS, BL et al. Food Chemistry: Acrylamide is formed in the Maillard Reaction. Nature 2002; 419: 448-9.

[37] Williams MJ, Sutherland WH, McCormick MP, de Jong SA, Walker RJ, Wilkins GT 1999. Impaired endothelial function following a meal rich in used cooking fat. J Am Coll Cardiol 1999; 33(4): 1050-5. 